\title{
All tyrosine kinase inhibitor-resistant chronic myelogenous cells are highly sensitive to Ponatinib
}

\author{
Ophélie Cassuto ${ }^{1-4 *}$, Maeva Dufies ${ }^{1} \mathbf{2}^{2 *}$, Arnaud Jacquel ${ }^{1-2}$, Guillaume Robert ${ }^{1} \mathbf{-}^{2}$,

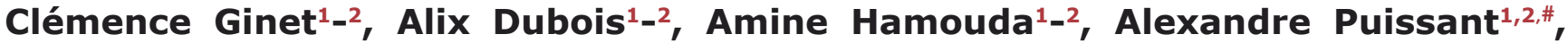 \\ Fredéric Luciano ${ }^{1}-^{2}$, Jean-Michel Karsenti ${ }^{3}$, Laurence Legros ${ }^{3}$, Jill Patrice Cassuto ${ }^{3}$, \\ Pascal Lenain ${ }^{4}$, Patrick Auberger ${ }^{1} \mathbf{z}^{3}$ \\ ${ }^{1}$ C3M/ INSERM U1065 Team Cell Death, Differentiation, Inflammation and Cancer, Nice, France \\ 2 Equipe Labellisée Ligue Nationale contre le Cancer 2011-2013, Paris, France \\ ${ }^{3}$ Service d'Hématologie Clinique et de Transplantation, CHU de Nice, France \\ ${ }^{4}$ Centre Henri Becquerel, CLCC, Rouen, France \\ \# Dana-Farber Cancer Institute, Pediatric-Oncology department, 450 Brookline Avenue, Boston, MA, USA \\ * denotes equal contribution \\ Correspondence to: Patrick Auberger, email: auberger@unice.fr \\ Keywords: CML, BCR ABL, TKI, Resistance, Ponatinib \\ Received: October 02, 2012, Accepted: November 12, 2012, Published: November 14, 2012 \\ Copyright: @ Cassuto et al. This is an open-access article distributed under the terms of the Creative Commons Attribution License, which \\ permits unrestricted use, distribution, and reproduction in any medium, provided the original author and source are credited.
}

\section{ABSTRACT:}

The advent of tyrosine kinase inhibitor (TKI) therapy has considerably improved the survival of patients suffering chronic myelogenous leukemia (CML). Indeed, inhibition of BCR-ABL by imatinib, dasatinib or nilotinib triggers durable responses in most patients suffering from this disease. Moreover, resistance to imatinib due to kinase domain mutations can be generally circumvented using dasatinib or nilotinib, but the multi-resistant T315I mutation that is insensitive to these TKIs, remains to date a major clinical problem. In this line, ponatinib (AP24534) has emerged as a promising therapeutic option in patients with all kinds of BCR-ABL mutations, especially the T315I one. However and surprisingly, the effect of ponatinib has not been extensively studied on imatinib-resistant CML cell lines. Therefore, in the present study, we used several CML cell lines with different mechanisms of resistance to TKI to evaluate the effect of ponatinib on cell viability, apoptosis and signaling. Our results show that ponatinib is highly effective on both sensitive and resistant $\mathrm{CML}$ cell lines, whatever the mode of resistance and also on BaF3 murine B cells carrying native BCR-ABL or T315I mutation. We conclude that ponatinib could be effectively used for all types of TKI-resistant patients.

\section{INTRODUCTION}

Chronic myelogenous leukemia (CML) is a disease of the hematopoietic stem cell, characterized by the $\mathrm{t}(9$; 22) $\mathrm{q}(34 ; \mathrm{q} 11)$ translocation encoding the oncoprotein BCR-ABL [1]. Patients suffering CML benefit from newtargeted therapies based on the use of tyrosine kinase inhibitors (TKIs). Three TKIs, imatinib, dasatinib and nilotinib that target BCR-ABL are routinely given with success as first or second-line treatment for this disease, but resistance occurs in a significant proportion of CML patients [2-4]. Several BCR-ABL-dependent mechanisms of resistance to imatinib have been identified, such as BCR-ABL point mutations involving or not the kinase domain or increased expression of BCR-ABL [5]. In addition to these BCR-ABL dependent events, several BCR-ABL independent mechanisms have been also reported, including increased expression and/or activation of tyrosine kinases including, the Src tyrosine kinases Lyn $[6,7]$ and Fyn $[8,9]$ and the receptor tyrosine kinase Axl $[10,11]$ as noticeable examples.

Regarding BCR-ABL kinase mutations, the multiresistant T315I one remains a crucial clinical challenge, since until recently, there is no effective treatment for 
the patients carrying this particular type of mutation. Ponatinib is a multi-targeted kinase inhibitor that exhibits high activity against the T315I mutation but also other BCR-ABL kinase mutants in vitro $[12,13]$. In addition, ponatinib has proven efficacy in mouse models of CML and was also found to be effective in a small cohort of patients with T315I mutations in two recent clinical trials $[12,14,15]$ (phase 1: NCT00660920; phase 2: NCT01207440; http://www.clinicaltrials.gov).

Surprisingly, although ponatinib represents a promising molecule for patients with BCR-ABL mutations, its mechanism of action has not been extensively studied, more particularly in imatinib-resistant CML cells with no BCR-ABL mutation. In this line, we have previously generated several imatinib-resistant cell lines from the parental K562, JURLMK1 and Lama CML cell lines $[8,16,17]$.

In the present study, we took advantage of the availability of these cell lines to evaluate the effect of ponatinib in comparison to other TKIs on cell metabolism, proliferation and apoptosis. In addition, we used the murine BaF3 cell line carrying either a wild-type BCRABL protein or its T315I and G250E mutated counterparts to decipher the mechanisms of action of this TKI. We show that ponatinib is highly efficient to induce cell growth inhibition and induction of apoptosis on different imatinib CML cell lines, whatever their mode of resistance.

\section{RESULTS}

The effect of ponatinib on the viability of several imatinib-resistant cell lines was evaluated in comparison with that of imatinib and dasatinib. Cell lines were incubated for $48 \mathrm{~h}$ with increasing concentrations of imatinib, dasatinib or ponatinib and cell viability was assessed using the XTT assay. We first investigated the effect of these ITKs on the viability of murine $\mathrm{Ba} /$ F3 cells, carrying wild type (WT) BCR-ABL, T315I or G250E-BCR-ABL mutation. As shown in Figure 1A, BaF3 cells expressing native BCR-ABL were highly sensitive to imatinib, dasatinib and ponatinib, whereas BaF3-T315I-BCR-ABL and BaF3-G250E-BCR-ABL cells were resistant to both imatinib and dasatinib. By contrast, ponatinib induced loss of cell viability in BaF3 cells carrying the T315I or G250E mutation, in agreement with previous results from the literature $[12,18]$. As expected, imatinib-resistant K562, Lama and JURLMK1 cell lines were resistant to high doses of imatinib and were also cross-resistant to dasatinib (Figure 1B, C and D). However, the three resistant cell lines exhibited high sensitivity to ponatinib, even though a higher concentration of ponatinib was necessary to achieve an equivalent loss of cell viability in sensitive versus resistant CML cells. Globally, high doses of ponatinib (30nM) efficiently killed all imatinib-resistant cell lines.

The IC50 values for the ponatinib effect's in parental
CML cells and for the different imatinib-resistant cells lines were very close ( 1 to $6 \mathrm{nM}$ versus 8 to $30 \mathrm{nM}$ ) (Figure $1 \mathrm{E})$. The IC50 values for imatinib were 0,15 to $0,5 \mu \mathrm{M}$ in parental cells versus more than $3 \mu \mathrm{M}$ in the resistant one. In addition, the IC50 values for dasatinib were 0.5 to $30 \mathrm{nM}$ in parental cells and 30 to more than $300 \mathrm{nM}$ in resistant cells. As a whole our findings confirmed the efficacy of ponatinib on the T315I mutation, but also highlighted the notion that ponatinib is effective on all types of imatinib-resistant CML cells, whatever their mode of resistance. Importantly, the IC50 values obtained for ponatinib in the present study for BaF3-WT-BCRABL, BaF3-T315I-BCR-ABL and BaF3-G250E-BCR$\mathrm{ABL}(1 \mathrm{nM}, 8 \mathrm{nM}$ and $8 \mathrm{nM}$ respectively) were very similar to the one reported previously by $\mathrm{O}$ ' Hare et al. $(0.5,11$ and 4.1nM respectively) [12].

Moreover, the IC50 values for parental K562 CML cells $(6 \mathrm{nM})$ and Lama CML cells $(1 \mathrm{nM})$ were also in good agreement with the one previously reported in the literature (3.9 and 0.5nM, respectively) [12].

\section{Ponatinib induces cell death in different TKI cell lines}

It is well established that TKIs induced different types of cell death, including apoptosis in CML cell lines $[8,9,11,16,19,20]$. Therefore, we next used Annexin V and $\mathrm{PI}$ staining to assess cell death in $\mathrm{Ba} / \mathrm{F} 3$ cells carrying wild-type or mutated BCR-ABL proteins and in CML cell lines treated with either a maximal dose of imatinib or increasing concentrations of ponatinib. Ponatinib was found to trigger apoptosis in both BaF3-WT and BaF3-T315I cells and to a less extend in BaF3-G250E cells (Figure 2A). Apoptosis induction by ponatinib was confirmed by the cleavage of poly-ADP-ribose polymerase (PARP), a caspase 3 substrate. Indeed, cleavage of PARP in its $85 \mathrm{kDa}$ fragment was detected in the three BaF3 cell lines (Figure 2A). Imatinib (1uM) was shown to significantly increased the number of Annexin $\mathrm{V}$ positive cells, a hallmark of apoptosis, in the K562, JURLMK1 and Lama CML cell lines, but not in their imatinib-resistant counterparts (Figure 2B, C and D). Ponatinib (10-30nM) was as efficient as 1uM imatinib to trigger apoptosis in the three sensitive cell lines. Conversely to imatinib, ponatinib was found to induce apoptosis in all three imatinibresistant cells lines, even though sensitivity to ponatinib was lower in K562R and LamaR cells as compared to JURLMK1R cells. Apoptosis induction by ponatinib was confirmed by PARP cleavage in each sensitive and resistant cell lines (Figure 2B, C and D). 


\section{Ponatinib inhibits the clonogenic potential of different TKI-resistant cell lines}

To investigate the effect of ponatinib on CML cell growth, we next performed clonogenic assays using the different Imatinib-sensitive and resistant cell lines described above. BaF3 cells carrying WT BCR-ABL protein failed to form colonies in soft agar in the presence of imatinib (Sup Figure 1A, blue histogram).

By contrast, BaF3 cells carrying the T315I or G250E-BCR-ABL mutation were fully resistant to imatinib treatment (Sup Figure 1A, red and green histograms). Importantly, ponatinib efficiently impaired colony formation in WT, T315I and G250E-BaF3 cell lines with a maximal effect at 10nM (Sup Figure 1A).

In addition, as illustrated on Sup Figure 1B, C and $\mathrm{D}$, the clonogenic potential of all imatinib-sensitive

A
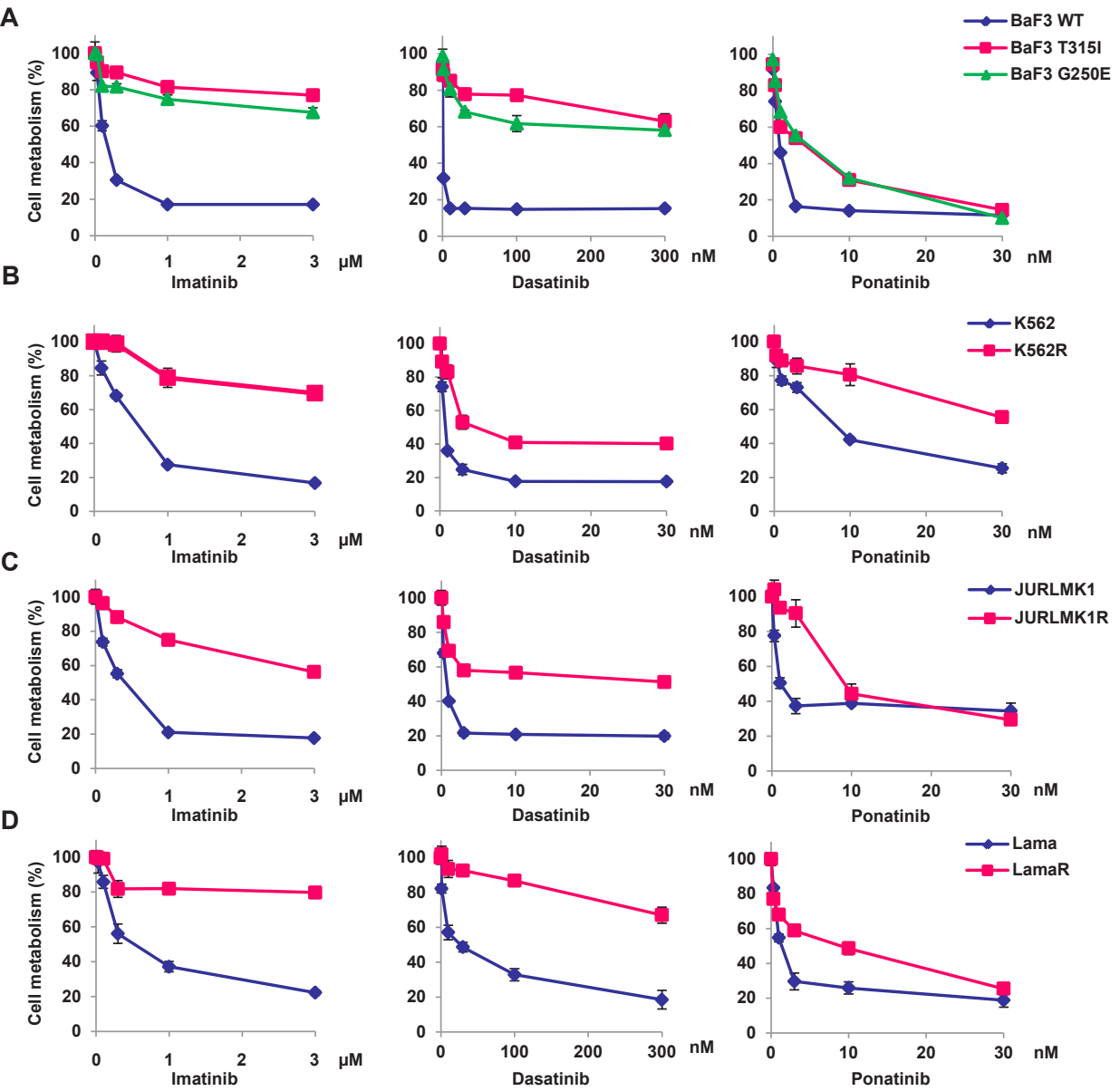

E

\begin{tabular}{|l|c|c|c|}
\hline & $\begin{array}{c}\text { IC50 }(\boldsymbol{\mu M}) \\
\text { Imatinib }\end{array}$ & $\begin{array}{c}\text { IC50 }(\mathbf{n M}) \\
\text { Dasatinib }\end{array}$ & $\begin{array}{c}\text { IC50 }(\mathbf{n M}) \\
\text { Ponatinib }\end{array}$ \\
\hline BaF3 WT & 0,15 & 1 & 1 \\
\hline BaF3 T315I & $>3$ & $>300$ & 8 \\
\hline BaF3 G250E & $>3$ & $>300$ & 8 \\
\hline K562 & 0,5 & 0.5 & 6 \\
\hline K562R & $>3$ & 3 & 30 \\
\hline JURLMK1 & 0,4 & 0.5 & 1 \\
\hline JURLMK1R & $>3$ & $>30$ & 10 \\
\hline Lama & 0,5 & 30 & 1.5 \\
\hline LamaR & $>3$ & $>300$ & 10 \\
\hline
\end{tabular}

Figure 1: Ponatinib induces a loss of viability in different TKI-resistant cell lines. (A to D) The BaF3 cell line (A) and the K562 (B), JURLMK1 (C) and Lama (D) CML cell lines were incubated for $48 \mathrm{~h}$ at $37^{\circ} \mathrm{C}$ with increasing concentrations of imatinib (left panel), dasatinib (middle panel) or ponatinib (right panel) or left untreated and cell metabolism was measured using the XTT assay as described in the materials and methods section. (E) IC50 values for each TKI are given for each cell lines. 
cell lines was abolished in the presence of low doses of imatinib (0.3 to $1 \mathrm{uM})$. As expected, all imatinib-resistant cells lines maintained high clonogenic potential in the presence this drug. Importantly, ponatinib induced a dosedependent decrease of the clonogenic potential of all three imatinib-resistant clones. Maximal inhibition was

A

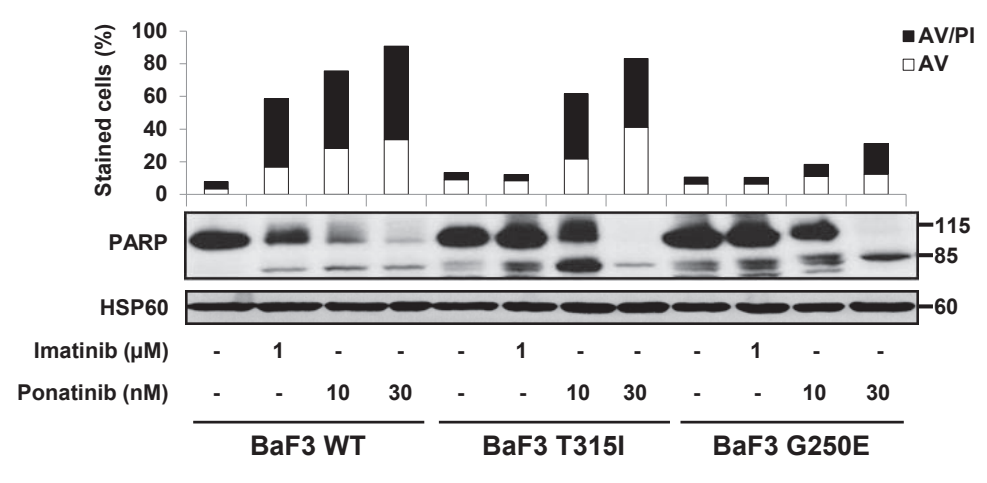

B

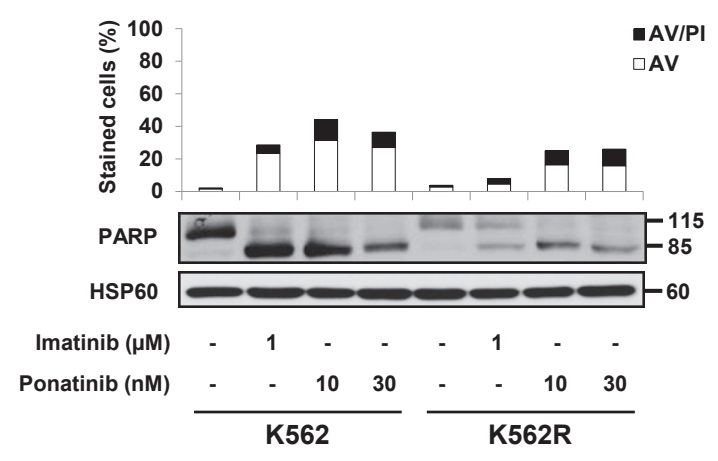

C

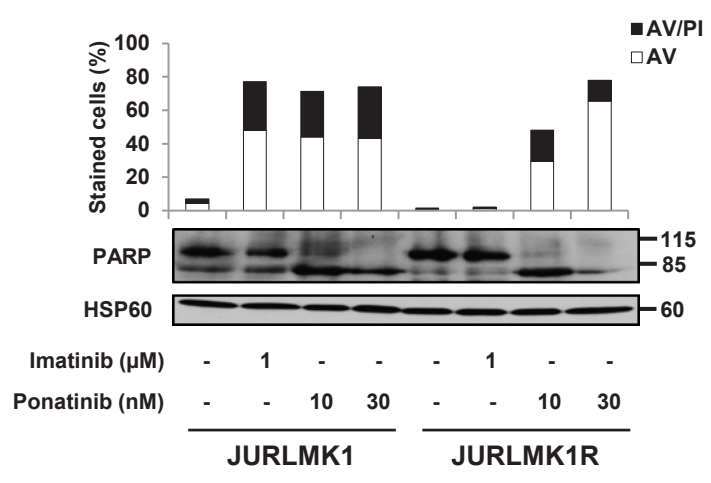

D

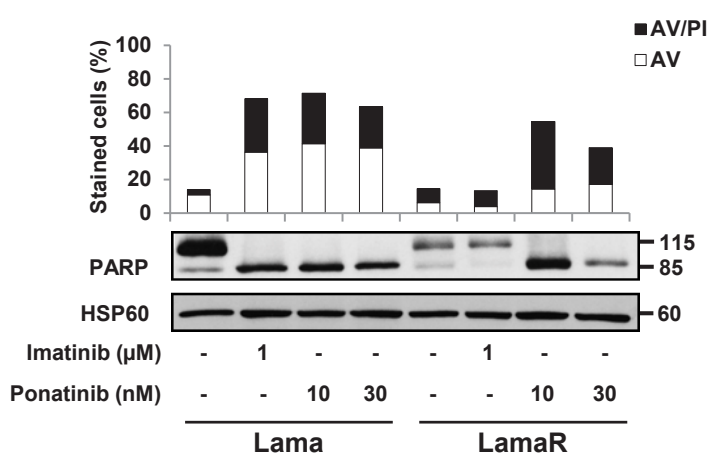

Figure 2: Ponatinib induces cell death in different TKI-resistant cell lines. The BaF3 cell line (A) and the K562 (B), JURLMK1 (C) and Lama (D) CML cell lines were incubated for $48 \mathrm{~h}$ at $37^{\circ} \mathrm{C}$ with either imatinib $(1 \mu \mathrm{M})$ or ponatinib $(10$ or $30 \mathrm{nM})$. Cells were then stained with the PI/ annexin-V-fluos staining kit according to the manufacturer's indications. Histograms show both annexin- $\mathrm{V}^{+} / \mathrm{PI}^{-}$cells (open bars) and annexin- $\mathrm{V}^{+} / \mathrm{PI}^{+}$cells (filled bars). Cleavage of PARP was analyzed by western blot in each cell line. 
achieved for 10 or $30 \mathrm{nM}$ of ponatinib depending on the cell line (Sup Figure 1A, B and C), JURLMK1 cells being highly sensitive to the effect of the drug (Sup Figure 1D). From the data described in Figures 1,2 and in Sup Figure
1, we conclude that ponatinib exerts its anti-leukemic effect in different imatinib-sensitive and resistant CML cell lines through both inhibition of their proliferative potential and induction of apoptosis.

A

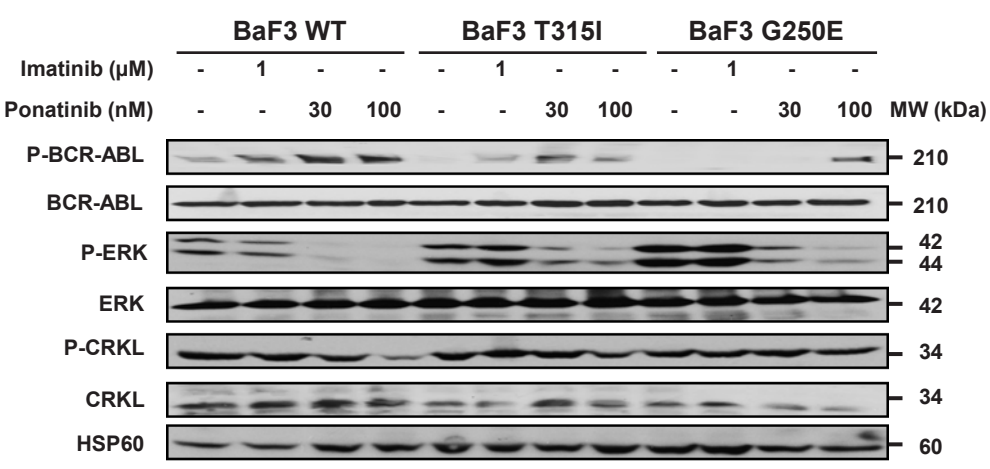

B
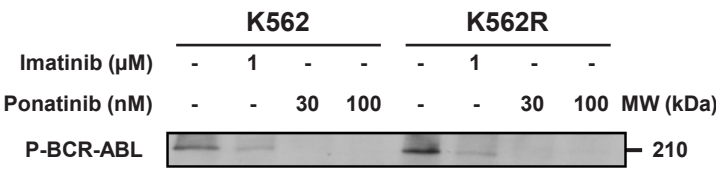

P-BCR-ABL

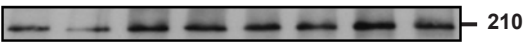

P-ERK

ERK $\div-\infty-\infty-\infty$

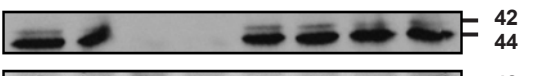

P-CRKL $\square-\square$

CRKL $\square-\infty-\infty-\square-34$

HSP60 —- $-\square-\square$

C
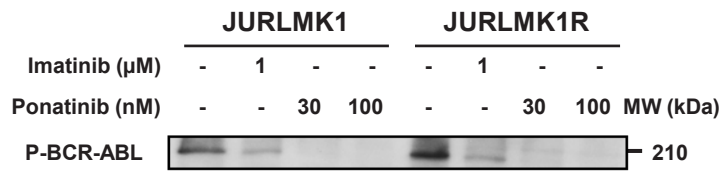

BCR-ABL $\square-\cdots-\cdots-\cdots$

P-ERK $\Longrightarrow=\equiv={ }_{44}^{42}$

ERK $=-=-=-12$

P-CRKL —- - 34

CRKL $\div-\infty-\cdots$

HSP60 ——— 60

D

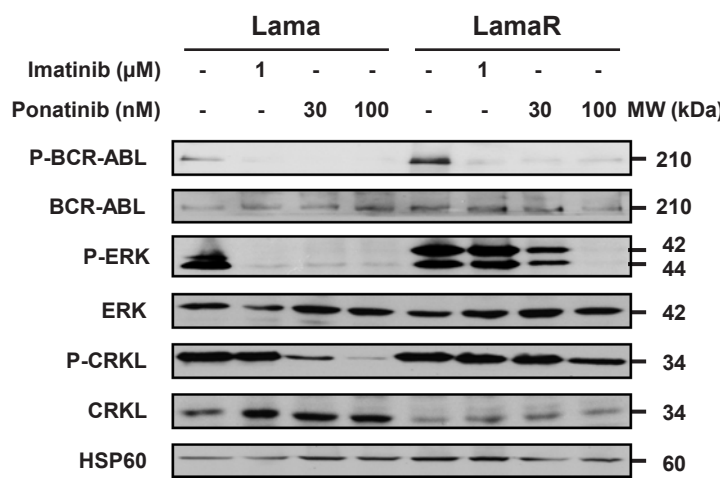

Figure 3: Ponatinib differently affects cell signaling in TKI-resistant cell lines. The BaF3 cell line (A) and the K562 (B), JURLMK1 (C) and Lama (D) CML cell lines were incubated for $4 \mathrm{~h}$ at $37^{\circ} \mathrm{C}$ with either imatinib $(1 \mu \mathrm{M})$ or ponatinib $(30 \mathrm{or} 100 \mathrm{nM})$. BCRABL, ERK and CRKL phosphorylation status and expression were analyzed by Western blotting. 


\section{Ponatinib differently affects cell signaling in TKI- resistant cell lines}

We next analyzed the effect of imatinib and ponatinib on signal transduction in the three $\mathrm{BaF} 3$ cell lines and in the different imatinib-resistant CML cell lines. To this end, we performed western blot analysis of several direct or indirect substrates of BCR-ABL. In BaF3-WTBCR-ABL and T315I cells, ponatinib efficiently inhibited
BCR-ABL phosphorylation, but dephosphorylation of CRLK necessitated higher doses of ponatinib (Figure 3A). Surprisingly, the effect of ponatinib was less pronounced on BaF3-G250E-BCR-ABL cells. As expected, Imatinib failed to inhibit BCR-ABL and CRKL phosphorylation in BaF3 cells carrying mutated BCR-ABL.

We have previously reported that K562R cells exhibited constitutive activation of ERK1/2 as a mechanism of resistance to this TKI $[9,17]$. Regarding the two other resistant cell lines (LamaR and

A
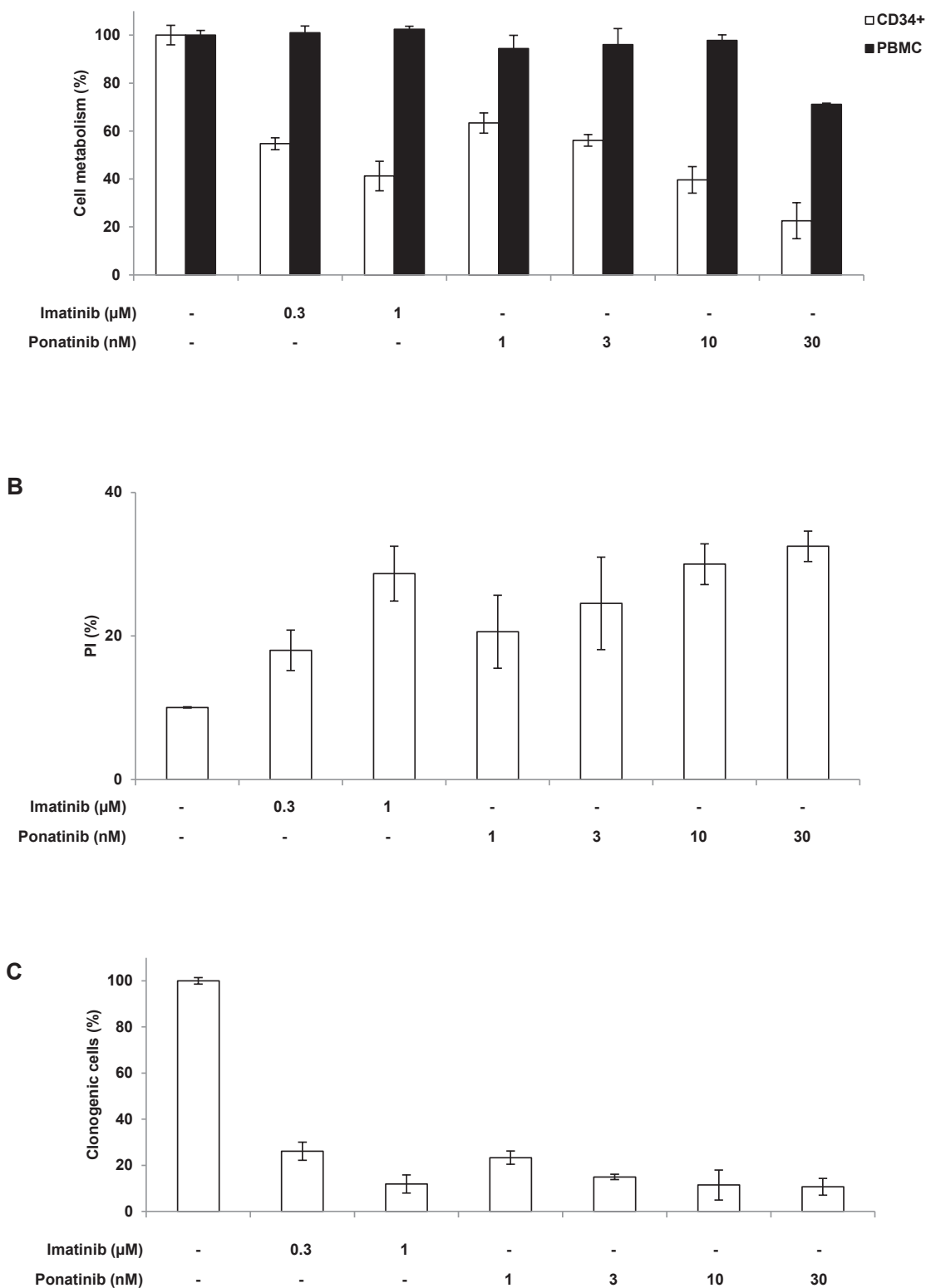

Figure 4: Ponatinib is highly efficient on CD34+ cells but not on PBMC from 2 CML patient at diagnosis. (A and $\mathrm{B}$ ) $\mathrm{CD}^{+} 4^{+}$or PBMC cells from two CML patients at diagnosis were incubated with different doses of imatinib (0.3 or $\left.1 \mathrm{uM}\right)$ or ponatinib ( 1 to $30 \mathrm{nM}$ ) for $48 \mathrm{~h}$ in IMDM complemented with $15 \%$ BIT, $100 \mathrm{ng} / \mathrm{ml} \mathrm{SCF,} \mathrm{100ng/ml} \mathrm{IL6} \mathrm{and} \mathrm{10ng/ml} \mathrm{IL3.} \mathrm{(A)} \mathrm{Cell} \mathrm{metabolism} \mathrm{was}$ assessed using the XTT assay as described in the materials and methods section. (B) Cells were stained with the PI staining kit according to the manufacturer's indications. (C) CML cells $\left(10 \times 10^{3}\right)$ growing in semi-solid methylcellulose medium were incubated with different concentrations of imatinib $(0.3$ or $1 \mathrm{uM})$ or ponatinib (1 to $30 \mathrm{nM})$. Results are expressed as the percentage of colony forming cells after drug treatment in comparison with the untreated control cells. 
JURLMK1R) the mechanism of resistance to imatinib is not fully understood but the data reported here in clearly show a constitutive activation of ERK1/2 also in these cells $[9,11]$. Nevertheless ponatinib inhibited BCR-ABL phosphorylation and, to a less extent CRKL phosphorylation (Figure 3B, C and D). Finally, maintenance of ERK1/2 activation was detected in JULMK1R and LamaR CML cells treated with ponatinib as it is the case in K562R cells (Figure 3B and [9]).

\section{Ponatinib is highly efficient on CD34+ cells but not on PBMC from a CML patient at diagnosis}

Finally, we assessed the effect of both imatinib and ponatinib on CD34+ cells from two CML patients at diagnosis. As expected Imatinib decreased CD34+ cell viability but failed to affect the viability of PBMC from the same patients. Ponatinib (30nM) was highly effective on CD34+ cells from the same patients with only a minor effect on PBMC at 30nM (Figure 4A). The effect of both TKIs accounted for by increased apoptosis as judged by AnnexinV/PI staining (Figure 4B). Finally both TKIs exhibits potent anti-proliferative effects on CD34+ cells as attested by a drastic loss of the ability of CD34+ to form colonies in soft agar (Figure 4C).

\section{DISCUSSION}

The findings described in the present study confirm and extend the work previously reported by O' Hare et al. in sensitive $\mathrm{CML}$ cell lines and $\mathrm{BaF} 3$ cells carrying native and mutated BCR-ABL [12]. However, our work is the first to investigate the effect of three different TKIs on a panel of imatinib-resistant cell lines. Our results indicate that ponatinib is effective on all CML cell lines in vitro, whatever the mode of resistance to imatinib. Interestingly, in our hands the cells carrying the G250E mutation seems less sensitive to the effect of ponatinib that the one carrying the T315I mutation. Indeed, dephosphorylation of BCR-ABL and CRKL by ponatinib is less effective in $\mathrm{BaF} 3$ carrying the G250E mutation. This is consistent with recent data from the literature that show an uncoupling between the IC50 values for BaF3 cellular proliferation assays and CRKL dephosphorylation by ponatinib [12]. Therefore, one interesting observation of the present study is the partial disconnection between BCR-ABL and CRKL phosphorylation.

CRKL is a direct substrate of BCR-ABL and therefore the status of CRKL phosphorylation is sought to be a reflect of the one of BCR-ABL. Although dephosphorylation of BCR-ABL by ponatinib was nearly complete at $10-30 \mathrm{nM}$, only a higher concentration of ponatinib $(100 \mathrm{nM})$ was capable to efficiently dephosphorylate CRKL. These results are in good agreement with those of $\mathrm{O}$ Hare et al. [12]. One possible explanation for the partial disconnection of BCR-ABL and CRKL phosphorylation would be that in imatinib-resistant cells, reactivation of other kinases including ERK1/2, Fyn and/or Lyn $[8,10]$ contributes to the regulation of CRKL phosphorylation independently on BCR-ABL. As higher concentrations of ponatinib are required to inhibit SRC kinases, this would bring a good explanation for the lesser sensitivity of Imatinib-resistant cells to ponatinib. In line with this hypothesis, we have previously reported that a Lyn/ERK1/2 axis is required for imatinib-resistance in K562 cells [9]. Therefore, it is tempting to speculate that the Lyn/ERK1/2 module could regulate CRKL phosphorylation independently of BCR-ABL. This hypothesis is reinforced by the observation that Lyn has been shown to recruit CRKL in neutrophils [21].

In conclusion, we show here for the first time that ponatinib is highly efficient to induce cell death in different imatinib-resistant CML cell lines. Phase II clinical trial evaluation of oral ponatinib in patients with refractory CML and other hematologic malignancies are ongoing. Our results suggest that in addition to T315I patients, ponatinib could be widely used in resistant CML patients, whatever the supposed mode of resistance to first line ITKs.

\section{MATERIALS AND METHODS}

\section{Reagents and antibodies:}

Imatinib mesylate (STI571, Gleevec) was purchased from Enzo Life Sciences (Farmingdale, NY, USA), and Dasatinib and Ponatinib were purchased from Selleckchem (Houston, TX, USA). RPMI 1640 medium, IMDM medium and fetal calf serum (FCS) were from life technologies (Carlsbad, CA, USA). Sodium fluoride, sodium orthovanadate, phenyl-methyl-sulfonyl fluoride (PMSF), aprotinin, leupeptin were purchased SigmaAldrich (France). Anti-HSP60 and anti-ERK antibodies were from Santa Cruz Biotechnology (Santa Cruz, CA, USA). HRP conjugated anti-mouse and anti-goat antibodies were from Dakopatts (Glostrup, Denmark). Anti-PARP, anti-phospho-ERK, anti-CRKL, anti-phosphoCRKL, anti-ABL, anti-phospho-ABL and peroxydaseconjugated anti-rabbit antibodies were obtained from Cell Signaling Technology (Beverly, MA, USA).

\section{Cell lines:}

Human CML cell lines K562, Lama, and JURLMK-1 were grown at $37^{\circ} \mathrm{C}$ under $5 \% \mathrm{CO} 2$ in RPMI supplemented with $10 \% \mathrm{FCS}, 50 \mathrm{U} / \mathrm{ml}$ penicillin, 50 $\mu \mathrm{g} / \mathrm{ml}$ streptomycin, and $1 \mathrm{mM}$ sodium pyruvate. K562, Lama and JURLMK-1 cells imatinib-resistant have been described earlier $[8,11]$. The BaF3 p210 BCR ABL WT, 
T31I and G250E cells were kindly provided by Pr. FX Mahon and have been described previously[22].

\section{Cell viability:}

Cells $(15 \times 103$ cells $/ 100 \mathrm{ml})$ were incubated in a 96 well plate with different effectors for the times indicated in the figure legends. Fifty microliters of sodium 3-[1-phenylaminocarbonyl)-3,4-tetrazolium]bis(4-methoxy-6-nitro) benzene sulfonic acid hydrate (XTT) reagent was added to each well. The assay is based on the cleavage of the yellow tetrazolium salt XTT to form an orange formazan dye by metabolically active cells. The absorbance of the formazan product, reflecting cell viability, was measured at $490 \mathrm{~nm}$. Each assay was performed in quadruplicate.

\section{Flow cytometry:}

After stimulation, cells were washed with ice-cold PBS and were stained with the annexin-V-fluos staining kit (Roche, Meylan, France) according to the manufacturer's procedure. Fluorescence was measured by using the FL2 channels of a fluorescence-activated cell sorter apparatus (Miltenyi cytometer).

\section{Western blot:}

After stimulation, cells were harvested and lysed in buffer containing 1\% Triton X-100 and supplemented with protease and phosphatase inhibitors (Roche Diagnostics). Lysates were pelleted, and $50 \mu \mathrm{g}$ of protein were analyzed by SDS-PAGE as described previously [23].

\section{Colony formation assay:}

TKI was added to cell lines growing in semisolid methylcellulose medium $(0.5 \times 103$ cells $/ \mathrm{ml}$; MethoCult H4236; StemCell Technologies Inc, Vancouver, BC, Canada). Colonies were detected after 10 days of culture by adding $1 \mathrm{mg} / \mathrm{ml}$ of 3-(4,5-dimethylthiazol- 2-yl)-2,5diphenyltetrazolium bromide (MTT) reagent and were scored by Image J quantification software (U.S. National Institutes of Health, Bethesda, MD, USA).

\section{Primary cell isolation:}

Blood samples were collected from patients newly diagnosed with CML. All patients were part of an institutional protocol. Peripheral blood mononuclear cells were isolated by density centrifugation (Ficoll-Paque Plus, Life Sciences). CD34+ cells were prepared by magnetic bead separation as described previously [20]. CD34+ cells from CML patients were grown at $37^{\circ} \mathrm{C}$ under $5 \% \mathrm{CO} 2$ in IMDM (Gibco BRL) supplemented with 15\% BIT (BSA Insulin Transferin) (Stem Cell Technologies), 100 ng/ml $\mathrm{SCF}, 100 \mathrm{ng} / \mathrm{ml}$ IL6 and $10 \mathrm{ng} / \mathrm{ml}$ IL3 were purchased from Miltenyi Biotec.

\section{AKNOWLEDGEMENTS}

This work was supported by The Ligue Nationale Contre le Cancer (LNCC, Equipe Labellisée 2011-2013), The Association pour la Recherche contre le Cancer (ARC), The Institut National de Cancéropoles (INCAPL-2010-219) and The Fondation de France. OC, GR and AJ A are fellowships from the Fondation pour la Recherche Médicale, the Fondation de France and the Ligue Nationale Contre le Cancer, respectively.

\section{REFERENCE}

1. Groffen J, Stephenson JR, Heisterkamp N, Bartram C, de Klein A, Grosveld G. The human c-abl oncogene in the Philadelphia translocation. J Cell Physiol Suppl. 1984; 3:179-191.

2. Santos FP, Kantarjian H, Quintas-Cardama A, Cortes J. Evolution of therapies for chronic myelogenous leukemia. Cancer J. 2011; 17:465-476.

3. Chomel JC, Turhan AG. Chronic myeloid leukemia stem cells in the era of targeted therapies: resistance, persistence and long-term dormancy. Oncotarget. 2011; 2:713-727.

4. Vakana E, Platanias LC. AMPK in BCR-ABL expressing leukemias. Regulatory effects and therapeutic implications. Oncotarget. 2011; 2:1322-1328.

5. Diamond JM, Melo JV. Mechanisms of resistance to BCRABL kinase inhibitors. Leuk Lymphoma. 2011; 52 Suppl 1:12-22.

6. Mahon FX, Hayette S, Lagarde V, Belloc F, Turcq B, Nicolini F, Belanger C, Manley PW, Leroy C, Etienne G, Roche S, Pasquet JM. Evidence that resistance to nilotinib may be due to BCR-ABL, Pgp, or Src kinase overexpression. Cancer Res. 2008; 68:9809-9816.

7. Gamas P, Marchetti S, Puissant A, Grosso S, Jacquel A, Colosetti P, Pasquet JM, Mahon FX, Cassuto JP, Auberger P. Inhibition of imatinib-mediated apoptosis by the caspase-cleaved form of the tyrosine kinase Lyn in chronic myelogenous leukemia cells. Leukemia. 2009; 23:15001506.

8. Grosso S, Puissant A, Dufies M, Colosetti P, Jacquel A, Lebrigand K, Barbry P, Deckert M, Cassuto JP, Mari B, Auberger P. Gene expression profiling of imatinib and PD166326-resistant CML cell lines identifies Fyn as a gene associated with resistance to BCR-ABL inhibitors. Mol Cancer Ther. 2009; 8:1924-1933.

9. Fenouille N, Puissant A, Dufies M, Robert G, Jacquel A, Ohanna M, Deckert M, Pasquet JM, Mahon FX, Cassuto 
JP, Raynaud S, Tartare-Deckert S, Auberger P. Persistent activation of the Fyn/ERK kinase signaling axis mediates imatinib resistance in chronic myelogenous leukemia cells through upregulation of intracellular SPARC. Cancer Res. 2010; 70:9659-9670.

10. Gioia R, Leroy C, Drullion C, Lagarde V, Etienne G, Dulucq S, Lippert E, Roche S, Mahon FX, Pasquet JM. Quantitative phosphoproteomics revealed interplay between Syk and Lyn in the resistance to nilotinib in chronic myeloid leukemia cells. Blood. 2011; 118:2211-2221.

11. Dufies M, Jacquel A, Belhacene N, Robert G, Cluzeau T, Luciano F, Cassuto JP, Raynaud S, Auberger P. Mechanisms of AXL overexpression and function in Imatinib-resistant chronic myeloid leukemia cells. Oncotarget. 2011; 2:874-885.

12. O'Hare T, Shakespeare WC, Zhu X, Eide CA, Rivera VM, Wang F, Adrian LT, Zhou T, Huang WS, Xu Q, Metcalf CA, 3rd, Tyner JW, Loriaux MM, Corbin AS, Wardwell S, Ning Y et al. AP24534, a pan-BCR-ABL inhibitor for chronic myeloid leukemia, potently inhibits the T315I mutant and overcomes mutation-based resistance. Cancer Cell. 2009; 16:401-412.

13. Zhou T, Commodore L, Huang WS, Wang Y, Thomas M, Keats J, Xu Q, Rivera VM, Shakespeare WC, Clackson T, Dalgarno DC, Zhu X. Structural mechanism of the PanBCR-ABL inhibitor ponatinib (AP24534): lessons for overcoming kinase inhibitor resistance. Chem Biol Drug Des. 2011; 77:1-11.

14. Huang WS, Metcalf CA, Sundaramoorthi R, Wang Y, Zou D, Thomas RM, Zhu X, Cai L, Wen D, Liu S, Romero J, Qi J, Chen I, Banda G, Lentini SP, Das S et al. Discovery of 3-[2-(imidazo[1,2-b]pyridazin-3-yl)ethynyl]-4-methyl$\mathrm{N}$-\{4-[(4-methylpiperazin-1-y l)methyl]-3-(trifluoromethyl) phenyl benzamide (AP24534), a potent, orally active paninhibitor of breakpoint cluster region-abelson (BCR-ABL) kinase including the T315I gatekeeper mutant. J Med Chem. 2010; 53:4701-4719.

15. O'Hare T, Deininger MW, Eide CA, Clackson T, Druker BJ. Targeting the BCR-ABL signaling pathway in therapyresistant Philadelphia chromosome-positive leukemia. Clin Cancer Res. 2011; 17:212-221.

16. Jacquel A, Colosetti P, Grosso S, Belhacene N, Puissant A, Marchetti S, Breittmayer JP, Auberger P. Apoptosis and erythroid differentiation triggered by Bcr-Abl inhibitors in CML cell lines are fully distinguishable processes that exhibit different sensitivity to caspase inhibition. Oncogene. 2007; 26:2445-2458.

17. Puissant A, Dufies M, Fenouille N, Ben Sahra I, Jacquel A, Robert G, Cluzeau T, Deckert M, Tichet M, Cheli Y, Cassuto JP, Raynaud S, Legros L, Pasquet JM, Mahon $\mathrm{FX}$, Luciano $\mathrm{F}$ et al. Imatinib triggers mesenchymallike conversion of CML cells associated with increased aggressiveness. J Mol Cell Biol. 2012; 4:207-220.

18. O'Hare T, Zabriskie MS, Eide CA, Agarwal A, Adrian LT, You H, Corbin AS, Yang F, Press RD, Rivera VM, Toplin J,
Wong S, Deininger MW, Druker BJ. The BCR-ABL35INS insertion/truncation mutant is kinase-inactive and does not contribute to tyrosine kinase inhibitor resistance in chronic myeloid leukemia. Blood. 2011; 118:5250-5254.

19. Jacquel A, Herrant M, Legros L, Belhacene N, Luciano F, Pages G, Hofman P, Auberger P. Imatinib induces mitochondria-dependent apoptosis of the Bcr-Abl-positive K562 cell line and its differentiation toward the erythroid lineage. FASEB J. 2003; 17:2160-2162.

20. Puissant A, Dufies M, Raynaud S, Cassuto JP, Auberger P. Targeting lysosomes to eradicate imatinib-resistant chronic myelogenous leukemia cells. Leukemia. 2010; 24:10991101.

21. He Y, Kapoor A, Cook S, Liu S, Xiang Y, Rao CV, Kenis PJ, Wang F. The non-receptor tyrosine kinase Lyn controls neutrophil adhesion by recruiting the CrkL-C3G complex and activating Rap1 at the leading edge. J Cell Sci. 2011; 124:2153-2164.

22. Robert G, Ben Sahra I, Puissant A, Colosetti P, Belhacene N, Gounon P, Hofman P, Bost F, Cassuto JP, Auberger P. Acadesine kills chronic myelogenous leukemia (CML) cells through PKC-dependent induction of autophagic cell death. PLoS One. 2009; 4:e7889.

23. Cluzeau T, Robert G, Mounier N, Karsenti JM, Dufies M, Puissant A, Jacquel A, Renneville A, Preudhomme C, Cassuto JP, Raynaud S, Luciano F, Auberger P. BCL2L10 is a predictive factor for resistance to azacitidine in MDS and AML patients. Oncotarget. 2012; 3:490-501. 